\title{
AXL Knock-Out in SNU475 Hepatocellular Carcinoma Cells Provides Evidence for Lethal Effect Associated with G2 Arrest and Polyploidization
}

\author{
Tugce Batur ${ }^{1,2} \mathbb{D}^{\mathbb{D}}$, Ayse Argundogan ${ }^{1,3}$, Umur Keles ${ }^{1} \mathbb{D}$, Zeynep Mutlu ${ }^{1}$, Hani Alotaibi ${ }^{1,2} \mathbb{D}$, Serif Senturk ${ }^{1,2, * \mathbb{D}}$ \\ and Mehmet Ozturk 1,4,*(D) \\ 1 Izmir Biomedicine and Genome Center, Dokuz Eylul University Health Campus, Izmir 35330, Turkey; \\ tugce.batur@ibg.edu.tr (T.B.); ayse.argundogan@msfr.ibg.edu.tr (A.A.); umur.keles@ibg.edu.tr (U.K.); \\ zynpmt186@gmail.com (Z.M.); hani.alotaibi@ibg.edu.tr (H.A.) \\ 2 Izmir International Biomedicine and Genome Institute, Dokuz Eylul University, Izmir 35330, Turkey \\ 3 School of Medicine, Dokuz Eylul University, Izmir 35340, Turkey \\ 4 Galen Research Center, Izmir Tinaztepe University, Izmir 35400, Turkey \\ * Correspondence: serif.senturk@ibg.edu.tr (S.S.); mehmet.ozturk@tınaztepe.edu.tr (M.O.)
}

check for

updates

Citation: Batur, T.; Argundogan, A.; Keles, U.; Mutlu, Z.; Alotaibi, H.;

Senturk, S.; Ozturk, M. AXL

Knock-Out in SNU475 Hepatocellular Carcinoma Cells Provides Evidence for Lethal Effect Associated with G2 Arrest and Polyploidization. Int. J. Mol. Sci. 2021, 22, 13247. https:// doi.org/10.3390/ijms222413247

Academic Editor: Hiroaki Taniguchi

Received: 8 November 2021

Accepted: 2 December 2021

Published: 9 December 2021

Publisher's Note: MDPI stays neutral with regard to jurisdictional claims in published maps and institutional affiliations.

Copyright: (c) 2021 by the authors. Licensee MDPI, Basel, Switzerland. This article is an open access article distributed under the terms and conditions of the Creative Commons Attribution (CC BY) license (https:/ / creativecommons.org/licenses/by/ $4.0 /)$.
Abstract: AXL, a member of the TAM family, is a promising therapeutic target due to its elevated expression in advanced hepatocellular carcinoma (HCC), particularly in association with acquired drug resistance. Previously, RNA interference was used to study its role in cancer, and several phenotypic changes, including attenuated cell proliferation and decreased migration and invasion, have been reported. The mechanism of action of AXL in HCC is elusive. We first studied the AXL expression in HCC cell lines by real-time PCR and western blot and showed its stringent association with a mesenchymal phenotype. We then explored the role of AXL in mesenchymal SNU475 cells by CRISPR-Cas9 mediated gene knock-out. AXL-depleted HCC cells displayed drastic phenotypic changes, including increased DNA damage response, prolongation of doubling time, G2 arrest, and polyploidization in vitro and loss of tumorigenicity in vivo. Pharmacological inhibition of AXL by R428 recapitulated G2 arrest and polyploidy phenotype. These observations strongly suggest that acute loss of AXL in some mesenchymal HCC cells is lethal and points out that its inhibition may represent a druggable vulnerability in AXL-high HCC patients.

Keywords: AXL; hepatocellular carcinoma; CRISPR-Cas9; gene knock-out; cell cycle arrest; DNA damage; polyploidy

\section{Introduction}

Hepatocellular carcinoma (HCC) affects more than 900,000 people each year, and it is the third most common cause of cancer-related deaths worldwide [1]. HCC patients have a low survival rate (median of survival is 9 months) and this tumor is extremely resistant to systemic chemotherapy [2]. Among solid cancers, HCC has one of the fewest druggable genetic alterations, limiting treatment options for advanced HCC [3]. Although, seven drugs for targeted therapy of HCC have been approved, their efficacy is limited. For example, systemic treatments with sorafenib, lenvatinib, regorafenib, cabozantinib, or ramucirumab provide median overall survival (mOS) rate ranging between 8.5 to 13.5 months [4].

A newly approved drug for second-line therapy, Cabozantinib, inhibits the activity of several receptor tyrosine kinases, including VEGFR, MET, and AXL, a member of the TAM (TYRO3, AXL, MER) family [5]. TAM family of receptors are expressed selectively in different normal cells, in particular, macrophages, and mediate the clearance of dead cells by efferocytosis [6,7]. For reasons not wholly understood, AXL is overexpressed in multiple solid cancers, including HCC, particularly during EMT (epithelial-mesenchymal transition), and acquired drug resistance. AXL is a critical player in cancer cell EMT [8,9] 
and the development of tumor metastasis and drug resistance in HCC $[8,10,11]$. It has recently been firmly established that AXL is the master regulator of EMT in HCC cells [8].

Previous reports that addressed the effects of AXL inactivation in different cancer cell models were based on knock-down by RNA interference or kinase activity inhibition by different small chemicals [10-15]. The main concern with these approaches is the inability to completely deplete AXL expression or fully inhibit its activity. Therefore, the effects observed under such conditions may reflect the consequences of a down-regulation of AXL activity rather than the lack of expression. This aspect is particularly important for mesenchymal HCC cell lines that overexpress AXL more than 100-fold compared to epithelial-like HCC cell lines associated with more than 15-fold upregulation of active phospho-AXL levels [8]. In order to achieve complete suppression of AXL expression, the best available method is gene inactivation by CRISPR/Cas9 targeting. However, this method appears to be highly ineffective for AXL inactivation in cancer cells. Indeed, to our knowledge, there is only one published example of studies related to phenotypic effects of AXL knock-out in the literature which has been reported in a mouse breast cancer cell line [16]. A previous attempt to inactivate the AXL gene by CRISPR/Cas9 technique in the SNU449 HCC cell line was unsuccessful [17]. Here we describe the successful inactivation of AXL expression in SNU475, a mesenchymal-like HCC cell line. We extensively characterized these AXL knock-out cells and have obtained new critical data. We demonstrate that the AXL expression is indispensable for SNU475 cell line to avoid DNA damage and cell cycle arrest leading to lethal polyploidization and loss of tumorigenicity.

\section{Results}

\subsection{AXL Has Elevated Expression in Mesenchymal-like HCC Cell Lines}

Based on previous studies associating the induction of AXL expression during EMT in cancer cells and reported studies on some HCC cell lines $[10,11,18,19]$, we decided to compare the relative expression of AXL in a large panel of HCC cell lines. As shown in Figure 1, we grouped our HCC cell lines as epithelial-like and mesenchymal-like according to previously reported classifications $[8,20]$. AXL transcripts and protein levels were analyzed by real-time PCR (qPCR) and Western Blot techniques, respectively (Figure 1). It was previously described that the AXL gene encodes two alternative spliced isoforms differing from each other by the presence or absence of exon 10 [21]. We called fulllength form AXL FL and the exon 10 missing short variant form AXL V (Figure 1A). In order to explore which of the isoforms is predominant in HCC cells, qPCR targeting exon 9-10 for AXL FL and exon 10-11 junction for AXL V were carried out. qPCR data are presented in Figure 1B,C for FL and V forms, respectively. Although the expression of the longer transcript (AXL FL) and its shorter counterpart (AXL V) was correlated, AXL FL was expressed at a higher rate than AXL V in mesenchymal-like HCC cell lines, Mahlavu, Focus, SNU449, SNU475, and SNU387. Both isoforms were undetected in epithelial-like HCC lines SNU398, Huh7, Hep3B, and HepG2. Of note, weakly positive AXL expression was detected in Hep40 cell line (Figure 1B,C, compare the y axis of two panels). At the protein level, increased expression was detected in mesenchymal-like HCC cell lines (Mahlavu, Focus, SNU182, SNU423, SNU449, SNU475, and SNU387). In contrast, epithelial-like HCC cell lines (HepG2, Hep3B, Hep3B-TR, Huh7, Hep40, and SNU398) displayed no or low expression, consistent with the results of qPCR for FL AXL mRNA (Figure 1D). 
A

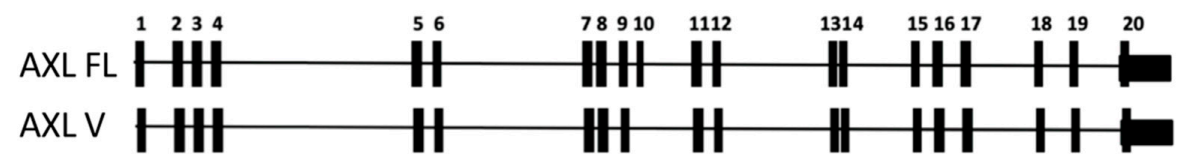

B

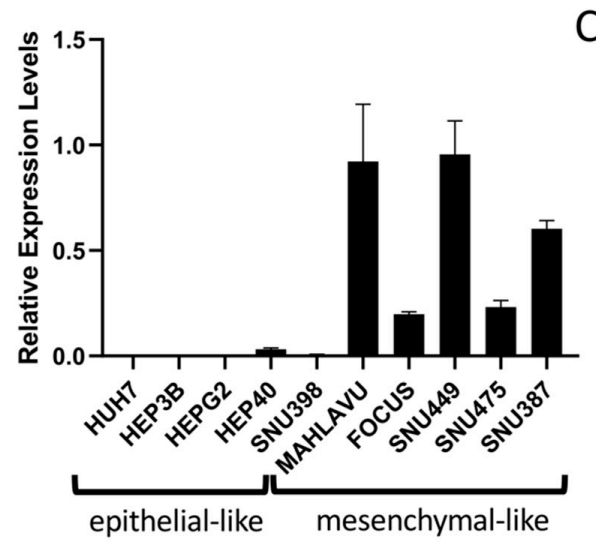

C

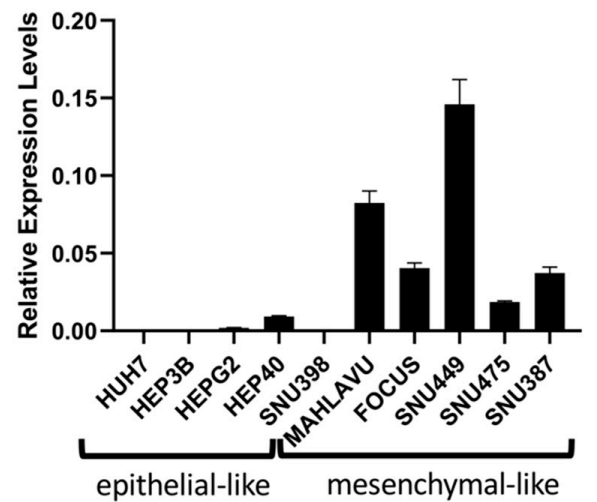

D

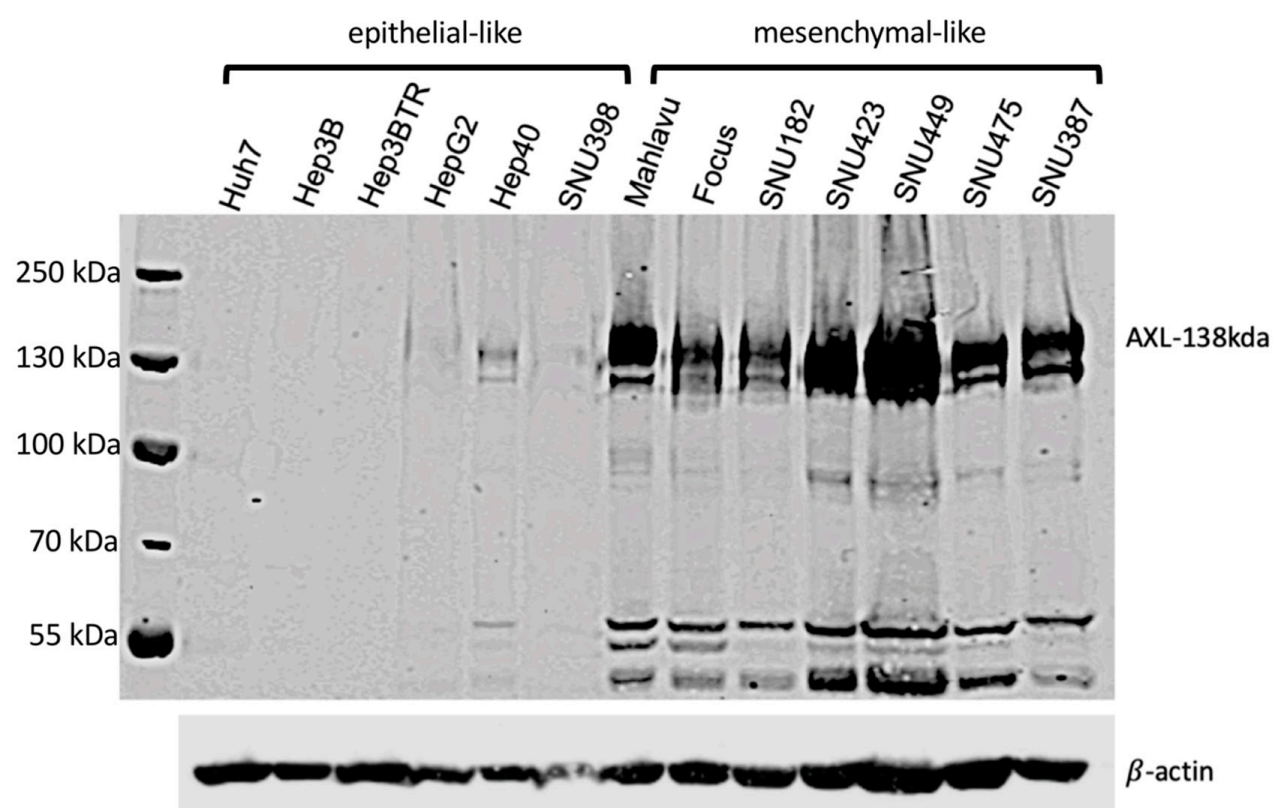

Figure 1. Expression Analysis of AXL in HCC Cell Lines. (A) The exon representations of the two alternative spliced isoforms of AXL. (B,C) mRNA levels of the long transcript, AXL FL, and short transcript, AXL V, were examined in 10 HCC cell lines using the real-time polymerase chain reaction (qPCR) technique. (D) Total proteins were analyzed in 13 HCC cell lines. $138 \mathrm{kDa}$ AXL protein and shorter AXL protein forms were detected in mesenchymal-like but not epithelial-like HCC cell lines. $\beta$-actin was used as a loading control.

\subsection{Successful Knockout of AXL Gene in SNU475 HCC Cell Line}

To elucidate the function of AXL in HCC, we performed CRISPR-Cas9-mediated AXL knock-out in Focus, Mahlavu, SNU449, and SNU475 cells lines that overexpress AXL, as demonstrated in Figure 1. To this end, we used two single guide RNAs (herein dubbed gRNA), AXL-45 and AXL-185, targeting AXL gene locus at two different sites (exon 1 and exon 2; shown in Figure S1) and non-targeting Renilla gRNA (specific to Renilla luciferase gene) served as the negative control. Similar to the previously reported findings in SNU449 cell line [17], 
AXL gene knock-out also proved relatively inefficient in all four HCC cell lines tested in this study. As compared to Renilla gRNA, AXL-185 gRNA caused a moderate decrease in AXL protein levels. In contrast, experiments with AXL-45 gRNA were more efficient, causing strong inhibition of expression as tested by western blot, albeit a total loss was not reached (Figure S2A). We noticed that the AXL expression in AXL gRNA-targeted cells was progressively returned initial levels in successive passages during cell culture (For example, Figure S2B for SNU449 cells, other cell lines not shown). This observation strongly suggested that cells that lost AXL expression suffer a survival disadvantage in the cell culture at the expense of AXL-expressing cell population. Therefore, we decided to increase our chances of obtaining AXL knockout cells by single cell cloning. Since AXL depletion was best achieved in SNU475 cells with AXL-45 gRNA (Figure S2A), we continued our experiments with this setup. Since the backbone plasmid of gRNAs had Venus gene (Figure S3A), Venus positive cells were sorted as single-cell using a cell sorter (Figure S3B-D). Single cell-derived clones were grown in culture and tested for AXL expression (Figure 2A). Many clones expressed low but detectable AXL expression. The expression of AXL was near background levels in clones c17 and c18 (Figure 2A). We could not expand the c18 clone, so we had to continue our further analyses with clone 17 , hereafter called AXL-c17 (Figure 2A).
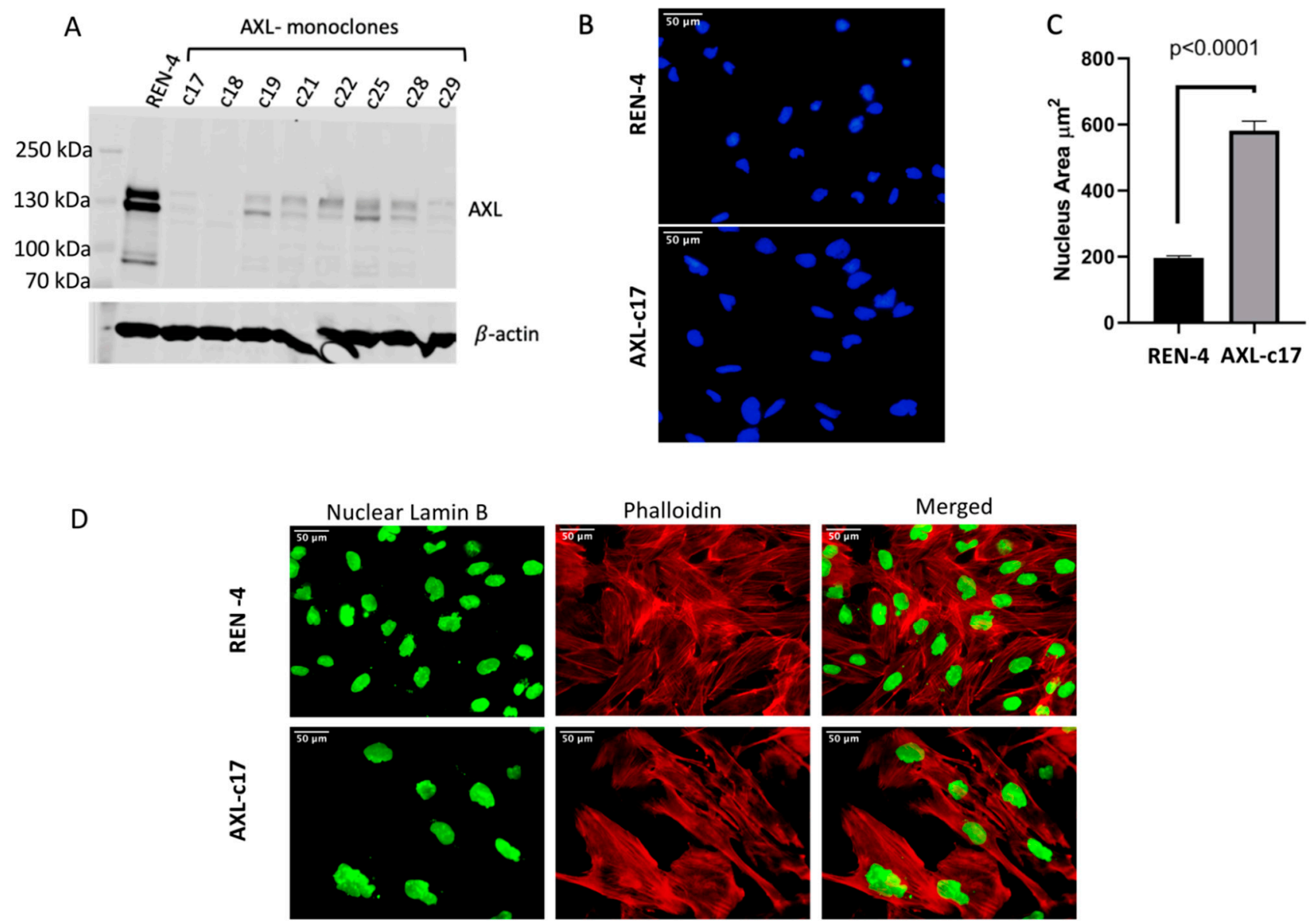

Figure 2. Expression levels of AXL in monoclones, REN-4 and AXL-c17, and changes in morphology and nucleus size. (A) $138 \mathrm{kDa}$ AXL expression was detected in REN-4 negative control cells and AXL-monoclones except for the c17 and c18. $\beta$-actin served as a loading control. (B) Nucleus staining by DAPI (blue) in REN-4 (top) and AXL-c17 (bottom). (C) Nuclear areas were calculated by Image J program. Significantly larger nucleus sizes were observed in AXL-c17 ( $p<0.0001)(\mathbf{D})$ Phalloidin (red) which stains F-actin protein, highlights the differences in cell morphology and nuclear lamin B (green) shows the nucleus differences. 


\subsection{Augmented Nucleus Size and Different Cellular Morphology of AXL Knock-Out SNU449 Clone AXL-c17}

In cell culture, AXL-c17 showed an aberrant change in cellular morphology compared with the control REN-4 clone. Therefore, we stained the nuclei of cells with DAPI $\left(4^{\prime}, 6-\right.$ diamidino-2-phenylindole) and calculated nuclear area by Image J program (Figure 2B). The average nuclear area of REN-4 control cells was about $200 \mu \mathrm{m}^{2}$. In contrast, we measured the average nuclear area of AXL knock-out AXL-c17 cells close to $600 \mu \mathrm{m}^{2}$ (Figure 2C). Thus, approximately a three-fold increase of nuclear area was detected in AXL-c17 cells $(p<0.0001)$ (Figure 2B,C). To further illustrate the differences in cellular morphology between AXL-c17 and REN-4 control cells, we studied the cytoskeletal arrangement by phalloidin staining and nuclear integrity by lamin B staining. As a result, AXL-c17 was frequently associated with increased nuclear size, accompanied by multinuclearity (Figure 2D).

\subsection{AXL Knock-Out Cells Exhibit Cell Cycle Aberrations, Polyploidy, and Low Clonogenicity}

To further explore the effects of AXL depletion in SNU475 cells, cell cycle analyses were carried out at $72 \mathrm{~h}$ post-seeding. Based on DNA content analysis, cell cycle distribution in control REN-4 cells was as expected, with the majority of cells being detected at the G1 phase $(>60 \%)$, followed by $S$ and G2 phases. Sub-G1 and polyploid (>G2) cells were both less than $3 \%$. In sharp contrast, however, AXL knockout c17 cells displayed gross cell cycle aberrations. Specifically, G1 cells dropped to less than 10\%, while G2 phase cells rose to almost $40 \%$. More interestingly, more than one-third of these AXL-depleted cells displayed polyploidy, as manifested by pseudotetraploidy. Finally, there was no significant difference in the number of sub-G1 cells (Figure 3A,B).

A

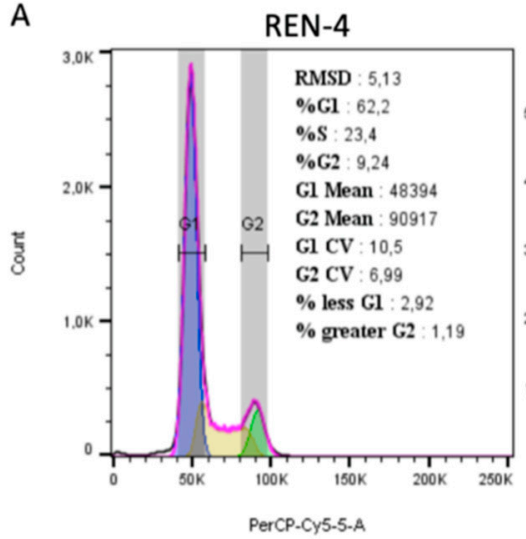

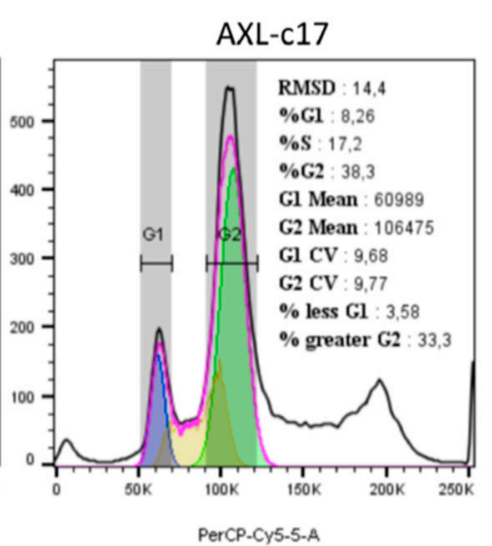

AXL-c17

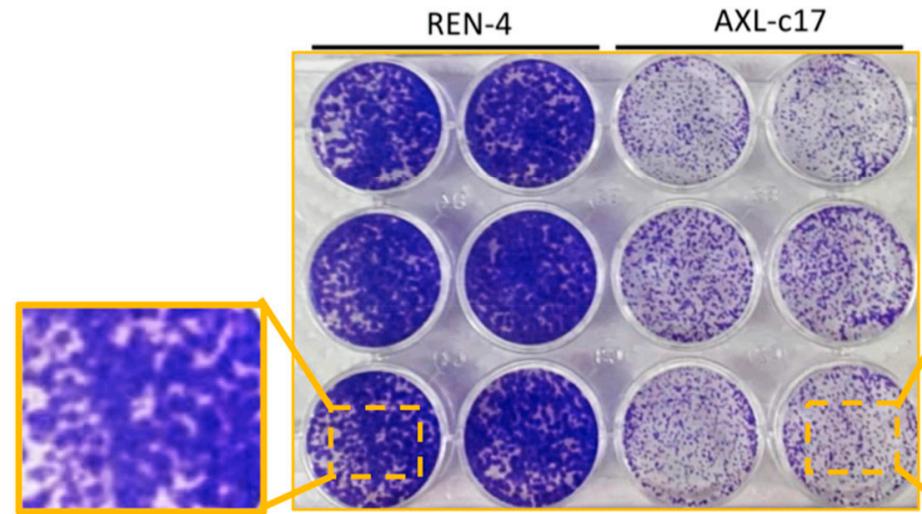

B

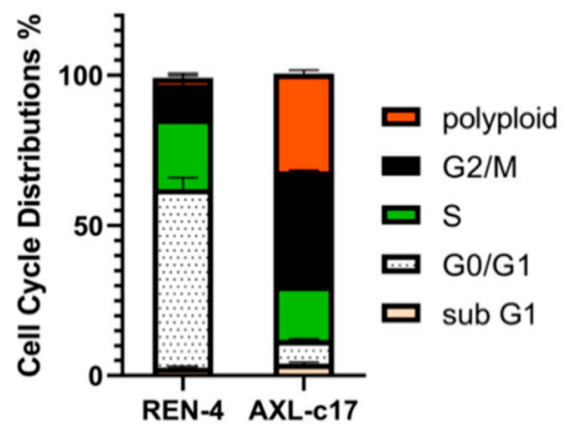

D

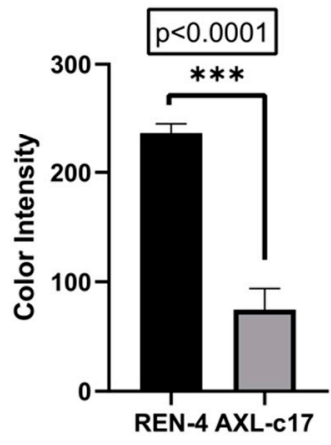

Figure 3. Cell cycle and colony formation of control and AXL knock-out cells. (A) DNA content from cell cycle analysis of REN-4 (left) and AXL-c17 (right) were shown. (B) Percentage of cell cycle distribution of both REN-4 and AXL-c17 cells. (C) Colony formation of REN-4 and AXL-c17 cells. Left 6 wells, and right 6 wells depict REN-4 and AXL-c17 cells, respectively. The focused area was displayed with dashed lines. (D) The color intensities of colony formations of REN-4 (black) and AXL-c17 (gray) were calculated by Image J. $\left.{ }^{* * *} p>0.0001\right)$. 
In accordance with the abundant polyploidy, AXL-c17 cells displayed crippled cell proliferation, as manifested by the formation of mini colonies (Figure 3C,D; $p<0.0001$ ). Based on these observations, we calculated the duplication times of REN-4 and AXLc17 cells in culture. Control cells had an average duplication time of $45.6 \mathrm{~h}$, whereas AXL-deficient c17 cells performed the same task at a mean rate of $75.9 \mathrm{~h}$.

\subsection{G2 Arrest and Polyploidization of AXL Knock-Out Cells Is Associated with Features of Unresolved DNA Damage Response}

Upon exposure to DNA damaging agents, cells expressing mutant p53 fail to undergo apoptosis or cease proliferation by arresting at G1 phase, and instead, they arrest at the G2 checkpoint [22-24]. Moreover, such G2-arrested cells can enter endoreduplication cycles resulting in the formation of polyploid cells over time [25]. Based on the fact that parental SNU475 cells display multiple p53 mutations [26], we hypothesized that the G2 arrest and polyploidization that we observed in these cells following genetic ablation of AXL gene was a manifestation of DNA damage response. To test our hypothesis, we performed a series of analyses to explore DNA damage response in AXL knock-out cells compared to control cells. DNA damage response is a complex process, which involves damage sensors (such as ATM and ATR) and mediators (such as 53BP1 and BRCA1), transducers such as Chk1 and Chk2, and effectors such as p53 and Cdc25 [27]. We first examined the number of nuclear foci decorated with phospho-ATM (Ser 1981) and 53BP1 by immunofluorescence and counted them (Figure 4A,B). Most of the control REN-4 cells displayed less than 10 foci per nucleus, whereas AXL knock-out c17 cells generally displayed more than 10 foci per nucleus (Figure 4A). Similar results were observed with 53BP1-positive foci. Specifically, AXL-c17 cells displayed mostly more than six foci, unlike REN-4 cells, which displayed less than 6 foci (Figure 4B).

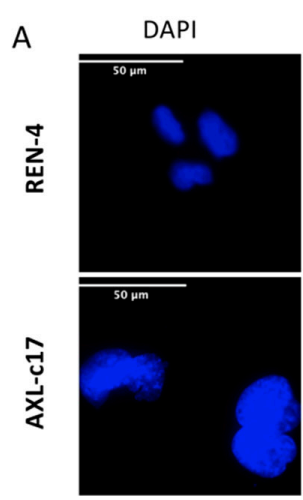

B

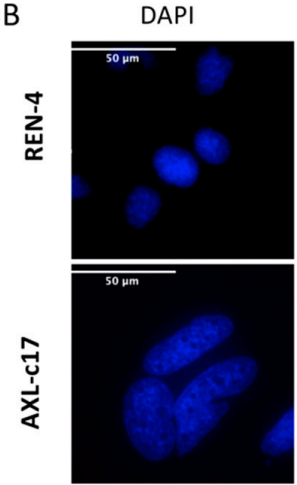

P-ATM

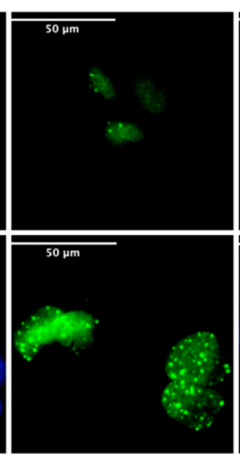

53BP1

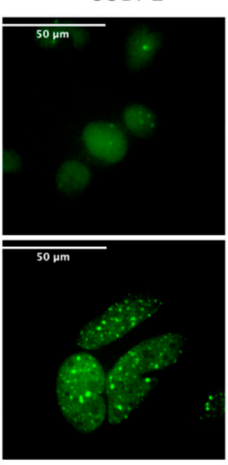

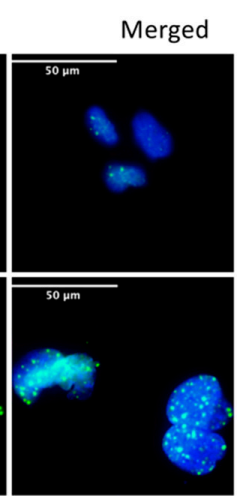

Merged

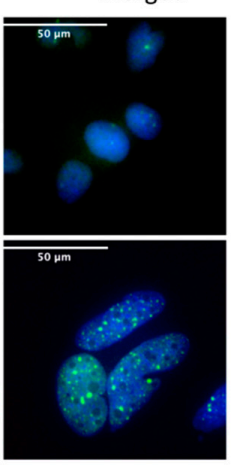

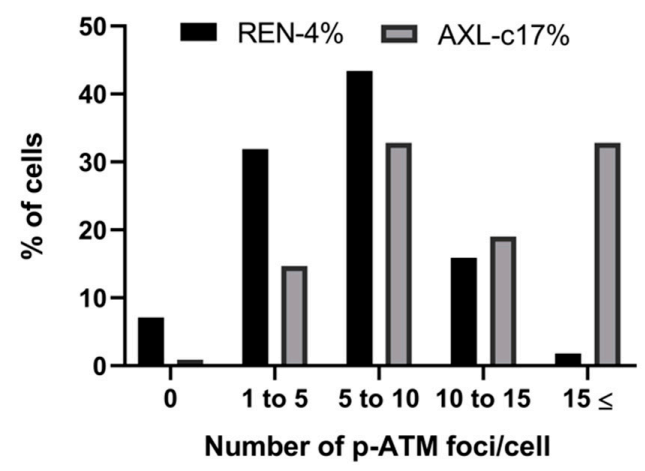

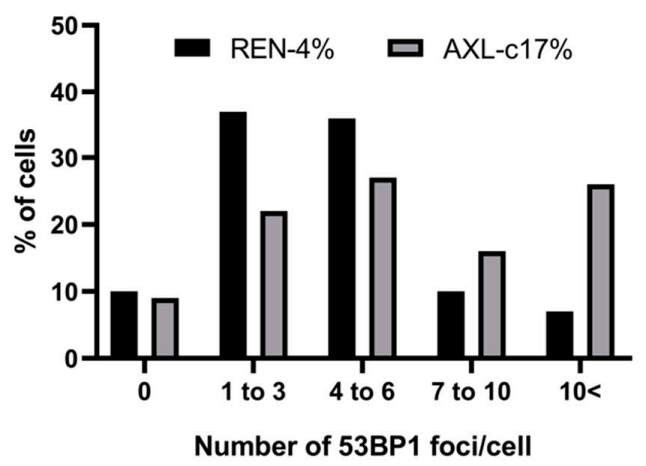

Figure 4. Foci formation as a marker of DNA damage response in AXL knock-out cells. Representative immunofluorescent image (left) and number of foci per cell distribution (right) of (A) p-ATM (Ser1981) and (B) 53BP1. Approximately 300 cells were counted for quantification. DAPI (blue) stains nucleus and foci were shown with green dots. The 53BP1 and p-ATM foci number per single cell was grouped as $0,1-3,4-6,7-10$, and greater than 10 , and $1-5,5-10,10-15$, and greater than 15 , respectively. 
Another outcome of DNA damage response is cellular senescence that can also occur after G2 arrest [22,28]. To elucidate the confounding accumulation in the G2 phase of the cell cycle, we tested whether cells entered senescence. HCC derived epithelial-like cell line, Huh7, was used as a positive control, and senescence was induced by treating cells with 50 and $100 \mathrm{nM}$ doxorubicin. Senescence morphology was observed in positive control Huh7 cells but not in doxorubicin-treated and non-treated SNU475 REN-4 and AXL-c17 cells, indicating that G2 arrest was not caused by cells entering senescence (Figure S4).

Findings reported here with AXL-c17 clone may represent the cellular effects of AXL gene inactivation and off-target effects of the CRISPR-Cas9 system. Therefore, we sought to obtain additional AXL knock-out clones from SNU475 cell line. We performed additional viral infection experiments on SNU475 cells using lentiviral vectors expressing gRNA, namely AXL-45 and AXL-185. Despite being a challenging task, after long efforts, we managed to derive only two additional clonal cell lines, namely 3-12C from AXL-45 and 6-10H from AXL-185 infections (Figure 5A,B). First, the lack of AXL expression was demonstrated by flow cytometry (Figure 5A) and western blot analyses (Figure 5B). Of note, all bands in REN-4 were related to AXL since we did not observe those in AXL knock-out clones Figure 5B). Previously generated AXL-c17 clone served as a control in these assays. Then, cell cycle analysis in early passage cells was shown in Figure 5C. These studies consistently yielded decreased G1 phase cells associated with a reciprocal increase in G2 phase and polyploid cells, but an increase in $\mathrm{S}$ phase cells was also detected. Compared to G1 phase cells observed at $67 \%$ in REN-4 cells, AXL-3-12C and AXL-6-10H cells displayed $33 \%$ and $30 \%$ G1 phase cells, respectively. This was accompanied by increased S phase ( $26-27 \%$ from $17 \%)$, G2 phase (15-20\% from $8 \%$ ), and polyploid cells (12-21\% from $2 \%$ ), as shown in Figure 5C.

A

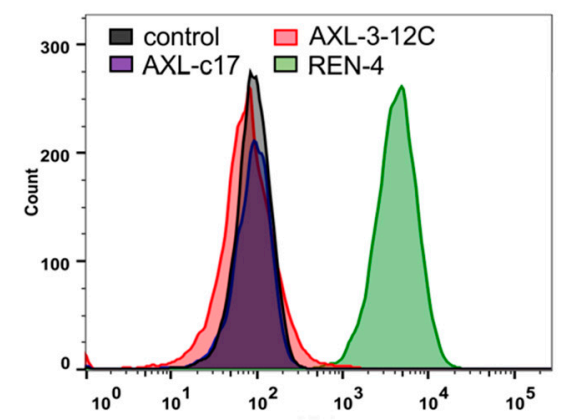

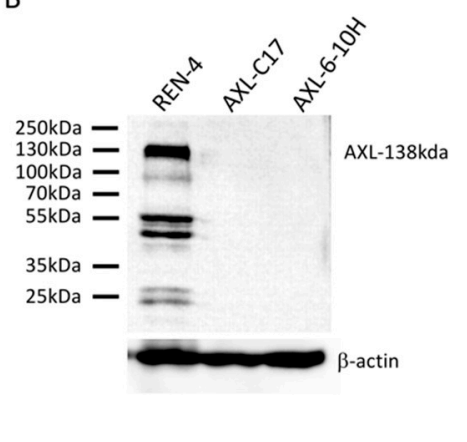

C
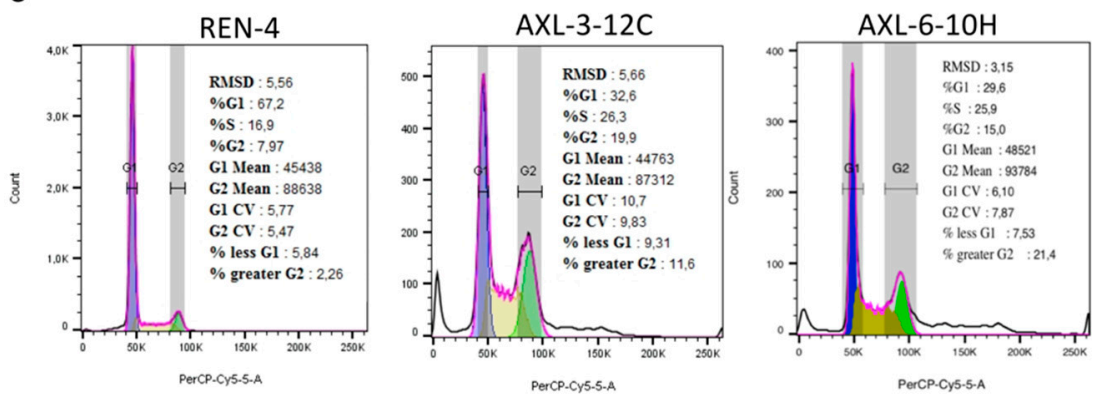

Figure 5. AXL expression and cell cycle analysis of newly obtained AXL knock-out clones, AXL-312C and AXL-6-10H. (A) AXL expression in REN-4, AXL-3-12C, AXL-c17 cells were analyzed by flow cytometry. Unstained control cells were used as a negative control. (B) AXL expressions of REN-4, AXL-c17, AXL-6-10H were analyzed by western blot. $\beta$-actin was used as a loading control. (C) Cell cycle distribution of control REN-4 and newly obtained AXL knock-out clones AXL-3-12C, AXL-6-10H, respectively. 
Much like other previously generated AXL knock-out clones, the AXL-3-12C isogenic clone failed to survive during extended periods of cell culture. Thus, we were able to perform additional experiments with AXL-6-10H and AXL-c17 clones only in comparison with REN-4 cells. Clonogenicity of these isogenic cell lines was assessed by plating flow cytometry sorted single cells into 96-well plates and following their survival and proliferation for 15 days using Cell Metric equipment. Representative examples of colony growth patterns are shown in Figure 6. REN-4-derived single-cell colonies displayed logarithmic growth, forming robust clonal groups populated with more than 200 cells (Figure 6A). In contrast, single cells derived from both AXL knock-out clones failed to form such colonies most of the time (Figure 6B,C), with rare exceptions. We tried to expand three different FACS-sorted single cell-derived clones from each subline, but we were successful with two AXL-c17 and only one AXL-6-10H-derived clones. Cell cycle analysis was performed on these clones to test whether they recovered from the aberration observed before single cellsorted cloning. As shown in Figure 6D, AXL knock-out cells remained growth-defective with G2 arrest and polyploidy.
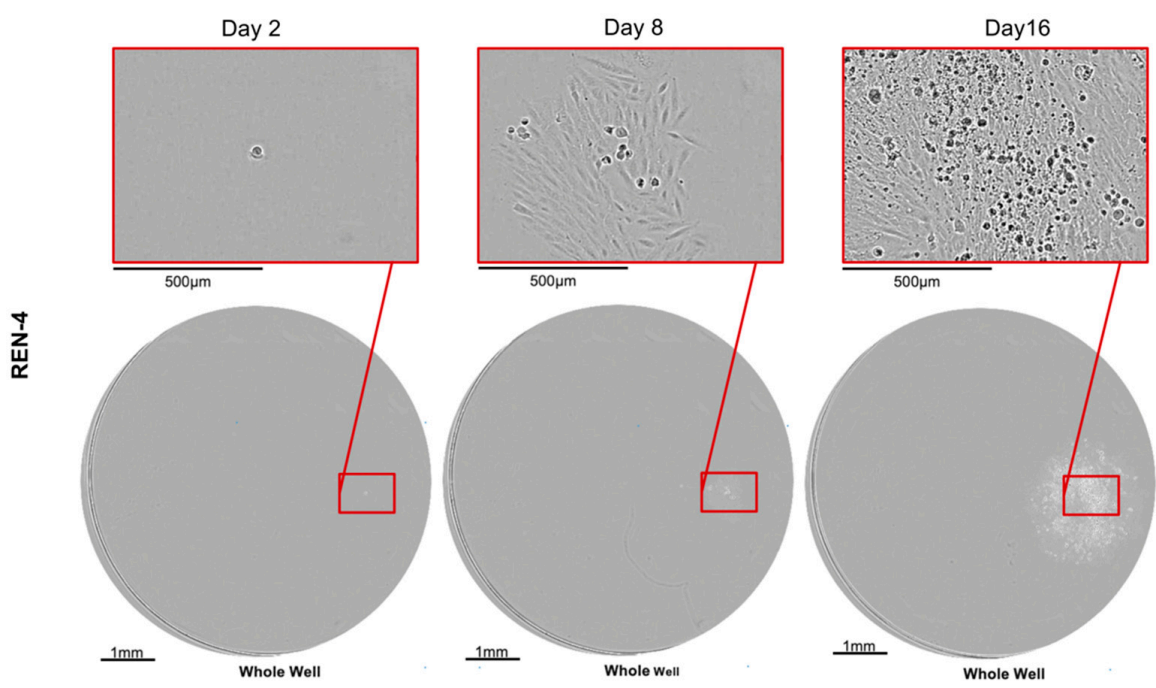

(A)
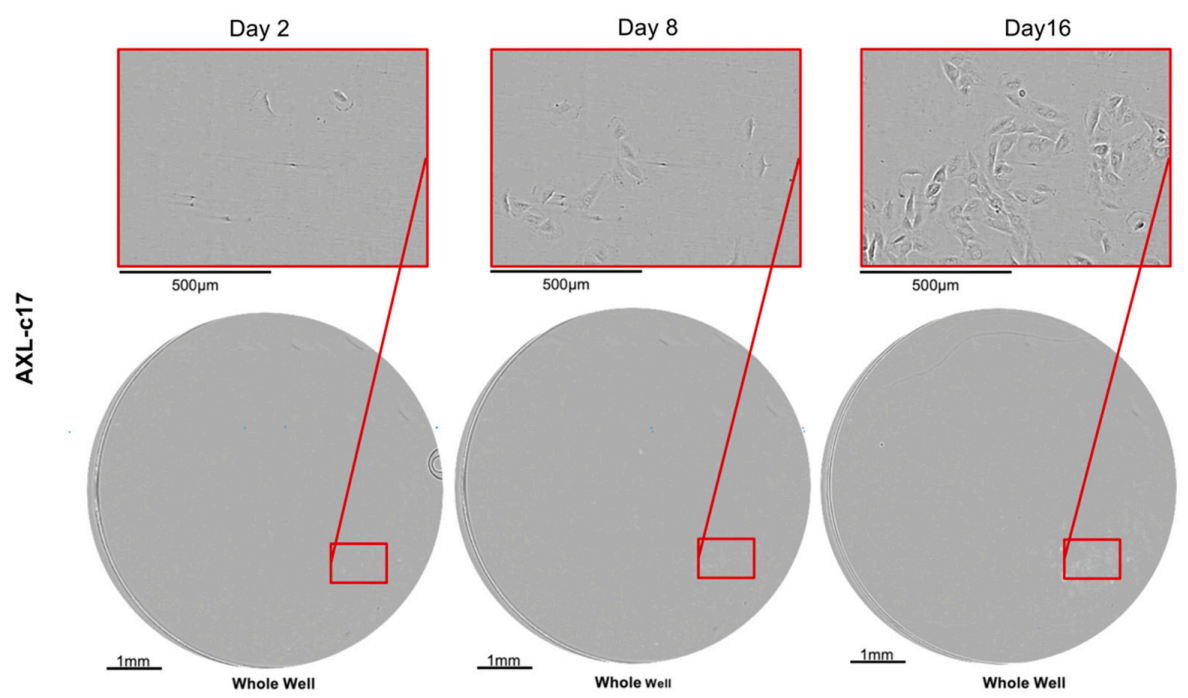

(B)

Figure 6. Cont. 

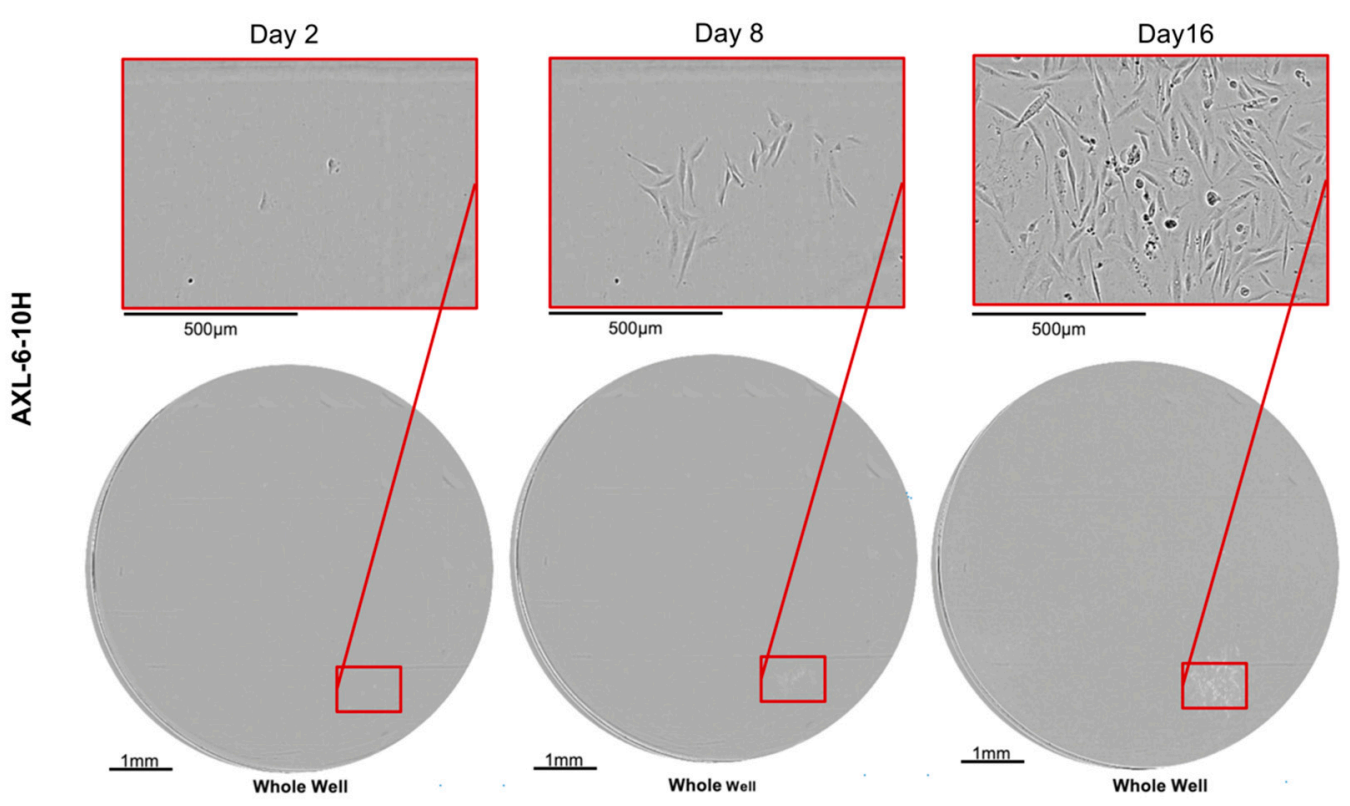

(C)
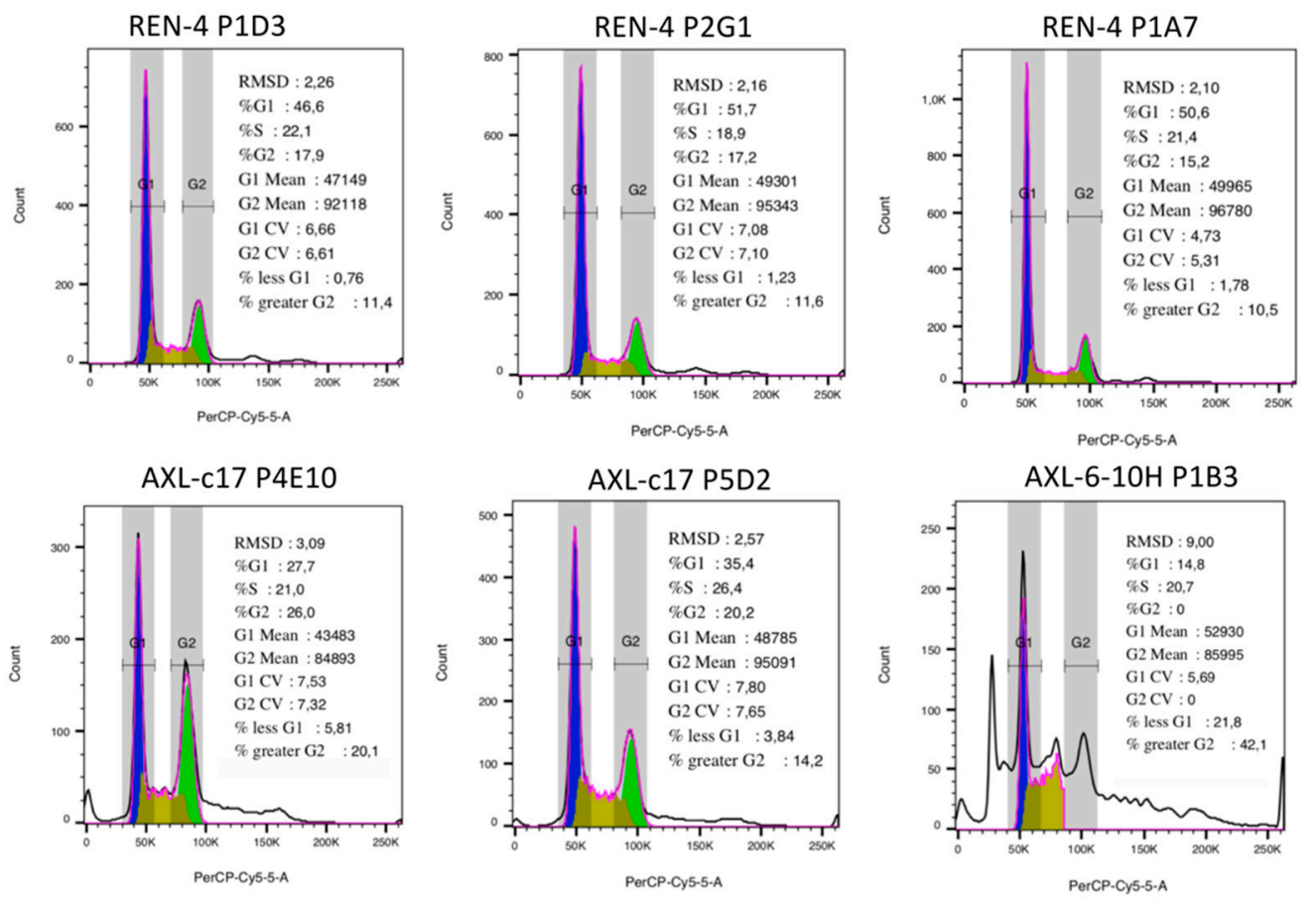

(D)

Figure 6. Clonality-proliferation assay and cell cycle distribution of single-cell clones REN-4, AXL-c17, AXL-6-10H. (A-C) Representative clonality-proliferation images of REN-4, AXL-c17, AXL-6-10H at days 2, 8, 16, respectively. (D) The cell cycle analyses of randomly selected clones from clonality-proliferation assay.

\subsection{Induction of G2 Arrest and Polyploidization by Pharmacological Inhibition of AXL in SNU475 Cells}

To confirm that the G2 arrest and polyploidization observed in AXL knock-out cells were indeed due to AXL loss of function, we treated the parental SNU475 cell line with a selective small molecule inhibitor of AXL, R428 (BGB324, Bemcentinib) [29]. The IC50 of parental cells was calculated as $3.2 \mu \mathrm{M}$ (Figure 7A). Parental SNU475 cells were treated for 24,48 , and $72 \mathrm{~h}$ with $1.5,3$, and $6 \mu \mathrm{M}$ R428 and subjected to cell cycle analysis. As shown in Figures S5 and 7B, we observed a dose-dependent increase in the percentage of G2 
phase and polyploid cells upon treatment with R418. This confirmed that these phenotypic changes were indeed due to pharmacological inhibition of AXL.

A

SNU475

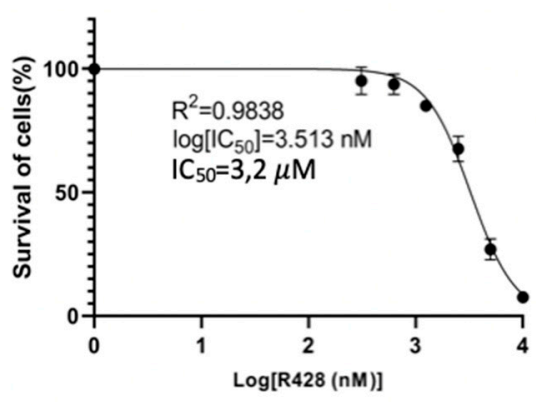

B

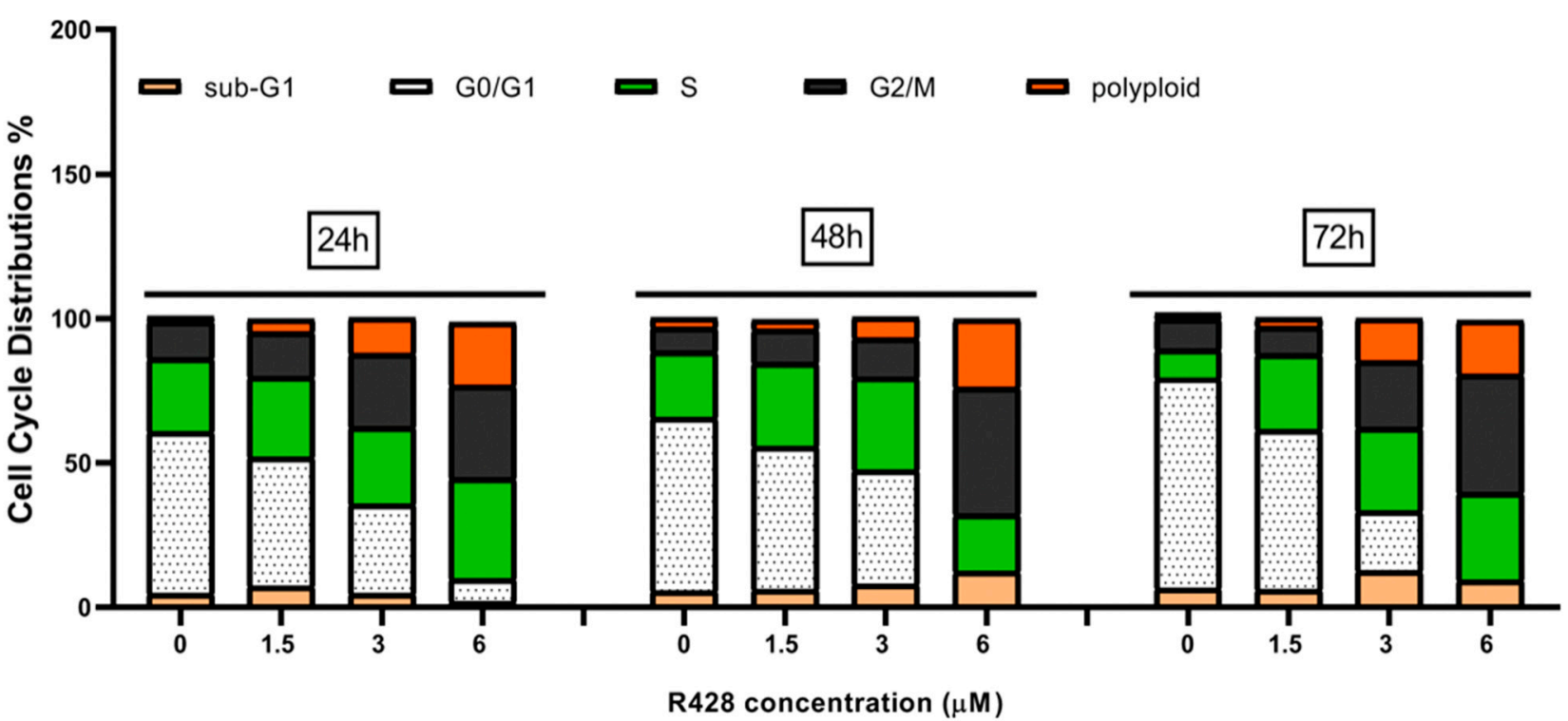

Figure 7. G2 cell cycle arrest was detected in AXL inhibitor R428-treated parental SNU475 cell line. (A) Cell survival curve versus $\log$ R428 concentration $(\mathrm{IC} 50=3.2 \mu \mathrm{M})$. (B) Cell cycle distribution of parental SNU475 cells versus increasing concentration of R428 at 24, 48, 72 h treatment. Sub-G1, G0/G1, S, G2/M, polyploid cells were colored in light orange, white, green, black, and orange, respectively.

\subsection{AXL Knock-Out Cells Lost Their Tumorigenic Ability}

Following in vitro experiments that showed the critical role of AXL in maintaining proliferation ability of mesenchymal-like SNU475 cells, we performed in vivo tumorigenicity studies as shown in Figure 8, using a total of ten immunodeficient NOD-SCID $\gamma$ mice, as described in Materials and Methods sections. Out of ten animals, one was deceased early in the experiment and therefore excluded from the study. As shown in Table 1, and Figure S6, control REN-4 cells were tumorigenic in all five animals tested. In sharp contrast, we detected no tumor formation in any of the four animals injected with AXL knock-out AXL-c17 cells after 10 weeks of follow-up ( $p=0.0042)$. As REN-4 clones were fully tumorigenic and AXL-c17 clones were not tumorigenic at all, we stopped in vivo studies at this stage for ethical reasons. 
Inject cells into mouse

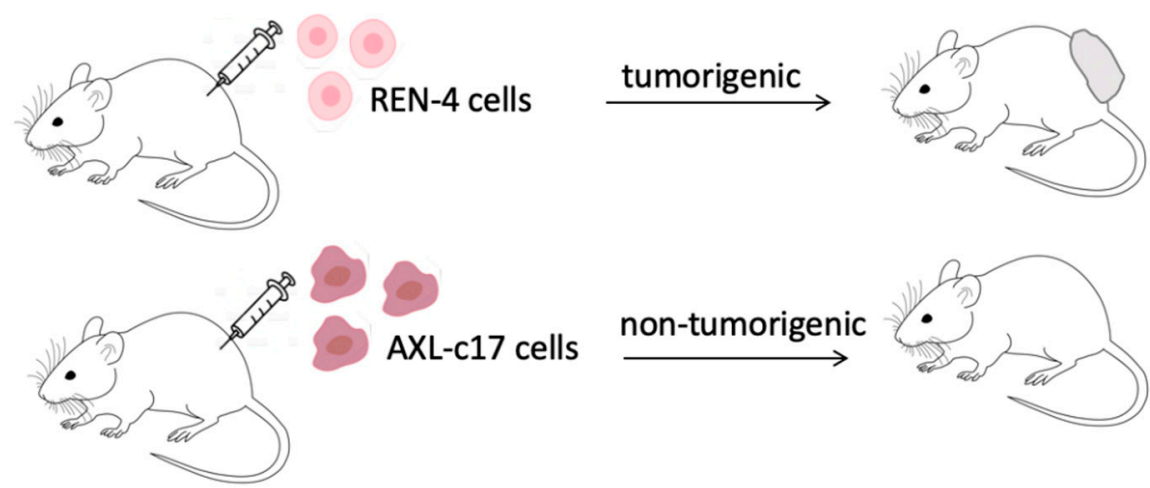

Figure 8. The scheme of animal experiments. Subcutaneous injection of control REN-4 cells induces tumor formation, whereas injection of AXL-c17 cells results in no tumor formation in all mice.

Table 1. Results of Tumor Formation experiments. The number of animals and injected cell number in each group is listed.

\begin{tabular}{ccc}
\hline Injected Cell Number & $\begin{array}{c}\text { Number of Animals with } \\
\text { Tumors } \\
\text { REN-4 }\end{array}$ & $\begin{array}{c}\text { Number of Animals with } \\
\text { Tumors } \\
\text { AXL-c17 }\end{array}$ \\
\hline $1 \times 10^{6}$ & $1 / 1$ & $0 / 1$ \\
$2 \times 10^{5}$ & $4 / 4$ & $0 / 3$ \\
\hline Total & $5 / 5$ & $0 / 4$ \\
\hline
\end{tabular}

\section{Discussion}

AXL is one of the several receptor kinases inhibited by Cabozantinib, a drug recently approved for the treatment of advanced HCCs [5]. The role of AXL inhibition in the efficacy of Cabozantinib treatment is not known. However, AXL is overexpressed in a subset of HCCs $[11,12,18,30,31]$. Its expression in clinical samples correlated with advanced tumor stage, multiple tumors, a higher incidence of vascular invasion, recurrence of disease, and mortality $[10,18,32]$. In addition, serum soluble AXL protein levels were reported as a new biomarker for HCC [33-35]. Phenotypic effects of AXL expression in HCC cell lines have been studied by RNA interference-mediated knock-down experiments. Downregulation of AXL expression attenuated cell proliferation, migration, and invasion in vitro and inhibited tumor metastasis in vivo $[11,18,19,36]$. Thus, the dramatic effects of AXL knock-out in SNU475 cells that we report here have not been observed before. RNA interference is based on the downregulation of mRNA, leading to a decrease in transcript levels instead of complete loss of function [37].

Our results indicate that AXL expression is closely correlated with a mesenchymal phenotype in HCC cell lines (Figure 1). This close correlation conforms with a recently published report demonstrating that the expression of AXL is the main driver of EMT in HCC cells [8]. The same study also reported that AXL is the most induced and most active tyrosine kinase expressed in mesenchymal HCC cells. Crippled survival of AXL knockout SNU449 cells that is observed here, as opposed to previously reported mild growth inhibitory effects, is probably a result of our experimental approach aiming at inactivation of AXL rather than downregulating its expression. This severe response appears to be due to increased DNA damage response in these cells in the absence of any external induction of DNA damage (Figure 4). Thus, in the absence of AXL, SNU475 cells are not able to deal with appropriate repair of DNA damage either because of increased damage load and/or decreased repair capacity. Increased DNA damage response following AXL inhibition has been reported for breast, ovarian, and lung cancer cell lines [14,38,39]. Here, we provide evidence that AXL knock-out alone is sufficient to block the survival of cancer cells by a mechanism associating G2 arrest with polyploidization (Figures 3, 5 and 6). G2 arrest and 
polyploidization have been observed in p53-deficient cancer cells following exposure to DNA damaging agents [25], although this has also been reported for p53-positive cells [40]. As SNU475 cell line displays multiple mutations, including p53 mutations [20,26], it will be interesting to further explore the mechanisms of polyploidization in these cells. However, this will be extremely difficult since these cells grow very poorly in cell culture (Figure 6). Finally, we show that R428, a well-known inhibitor of AXL kinase activity, also induced G2 arrest and polyploidy in SNU475 cells, albeit less severely (Figure 7). Since this small chemical is quite active on different HCC cell lines, its growth inhibition could be mediated by G2 arrest and polyploidization as described here for SNU475 cells.

We would like to conclude by stressing that our observations about AXL dependency of mesenchymal HCC cells are based on a single cell line. As displayed in Figure 2A, our attempts to obtain additional AXL-knockout clones from several other mesenchymal HCC cell lines were unsuccessful. Therefore, it is presently unknown whether AXL dependency for survival is restricted to SNU475 cells or applicable to additional mesenchymal HCC cell lines. Further investigations are required for a better understanding of AXL roles in mesenchymal HCC cells.

\section{Materials and Methods}

\subsection{Cell Culture}

Epithelial-like (Hep3B, Hep3B-TR, Huh7, HepG2, Hep40, SNU398) and mesenchymallike (Mahlavu, Focus, SNU387, SNU182, SNU423, SNU449, SNU475) HCC cell lines were used in the experiments [8,41,42]. The authenticity of these cell lines was confirmed by STR analysis. All cell lines were maintained in complete RPMI medium (11875168, Thermo Fisher Scientific, Waltham, MA, USA) supplemented with 10\% FBS (16000036,Thermo Fisher Scientific, Waltham, MA, USA), 1\% penicillin-streptomycin (15140148,Thermo Fisher Scientific, Waltham, MA, USA ), and $1 \%$ non-essential amino acid mixture (10270106, Thermo Fisher Scientific, Waltham, MA, USA) at $37^{\circ} \mathrm{C}$ with $5 \% \mathrm{CO}_{2}$.

\subsection{Antibodies}

Anti-AXL (C89E7, Cell Signaling, Danvers, MA, USA), anti- $\beta$-actin (8226, Abcam, Cambridge, MA, USA) antibodies were used in western blot assays. Lamin B (M-20,Santa Cruz Biotechnology, Dallas, TX, USA), Alexa Fluor 568 Phalloidin (A12380, Thermo Fisher, Waltham, MA, USA), 53BP1 (4937S, Cell Signaling, Danvers, MA, USA), and p-ATM Ser1981 (D25E5, Cell Signaling, Danvers, MA, USA) were used in immunofluorescence, and PE-conjugated anti-human AXL antibody (FAB154P, R\&D Systems, Minneapolis, MN, USA) was used in the flow cytometry.

\subsection{Cloning}

pECPV (EFS-Cas9-P2A-Venus) vector was used as the backbone plasmid in CRISPRCas9 knock-out experiments. This backbone was derived from lenticrispr V2 vector (Addgene plasmid \#52961) by successfully replacing Puromycin resistance coding sequence with the Venus gene, which encodes an improved version of the yellow fluorescent protein (YFP). Details on the creation and design of the backbone were described previously [43]. Cloning procedure was carried out as described by Shalem et al. [44]. Briefly, pECPV vector was digested with BsmBI enzyme (ER0451, Thermo Fisher, Waltham, MA, USA) and dephosphorylated with FastAP (EF0654, Thermo Fisher, Waltham, MA, USA). Oligonucleotides used in the cloning of gRNAs (listed in Table S2) were phosphorylated by T4 PNK (M0201S, NEB, Ipswich, MA, USA) and annealed using a thermal cycler program set to $30 \mathrm{~min}$ at $37^{\circ} \mathrm{C}, 5 \mathrm{~min}$ at $95{ }^{\circ} \mathrm{C}$, and ramp down to $25^{\circ} \mathrm{C}$ at $5^{\circ} \mathrm{C} / \mathrm{min}$. Annealed and phosphorylated oligonucleotides and digested backbone plasmid were ligated with Quick Ligase (M2200S, NEB, Ipswich, MA, USA) and transformed into Stbl-3 bacteria. 


\subsection{Viral Packaging and Transduction}

Packaging of the viral particles was accomplished by co-transfecting with packaging plasmids pLP1, pLP2, and pVSVG (Invitrogen, Carlsbad, CA, USA) and gRNA containing pECPV vectors into Hek-293T packaging cells using Lipofectamine 2000 reagent (Thermo Fisher, Waltham, MA, USA). The supernatants containing the viral particles were collected and filtered at $48 \mathrm{~h}$ post-transfection. Cells were transduced with the viral particles at a $1 / 20$ dilution. Three days after transduction, Venus signal was assessed using BD LRS Fortessa flow cytometry (BD Bioscience, San Jose, CA, USA).

\subsection{Obtaining Monoclones}

Venus positive cells were sorted into 96-well plates as single-cell/well, using BD Cell Sorter ARIAIII (BD Bioscience, San Jose, CA, USA). The growth of cell colonies was routinely controlled under a microscope, and when sufficient growth was observed, they were transferred into 6-well plates and so on.

\subsection{Western Blot}

When the confluency reached about 70-80\%, the cells were detached with trypsin and rinsed with PBS, and the cell pellets were collected by centrifugation. After discarding the supernatant, the pellets were lysed in a modified RIPA buffer $(150 \mathrm{mM} \mathrm{NaCl}, 1 \%$ Nonidet P-40, 0.5\% Sodium deoxycholate, \%0.1 SDS, and $25 \mathrm{mM}$ pH7.4 Tris, $1 \mathrm{mM}$ PMSF, $1 \mathrm{mM}$ $\mathrm{NaF}, 1 \mathrm{mM} \mathrm{Na} \mathrm{VO}_{4}$ ). For protein extraction, the tubes were kept on ice for 20-30 min by occasional vortexing every $3-4 \mathrm{~min}$. The tubes were then centrifuged at $15,000 \times g$ for $30 \mathrm{~min}$, and protein extracts were quantified using the Pierce BCA Assay Kit (ThermoFisher, Waltham, MA, USA). Total protein samples were denatured in $4 \times$ loading dye containing $20 \%$ of $\beta$-mercaptoethanol at $95^{\circ} \mathrm{C}$. Protein samples and protein size markers were then loaded on SDS-PAGE gel composed of $8 \%$ or $10 \%$ resolving and $5 \%$ stacking gels. Initially, $70 \mathrm{~V}$ was applied to the gel cast to allow the samples to pass through the stacking gel. Then, the proteins were run on the resolving gel with a voltage of $110 \mathrm{~V}$ for $2 \mathrm{~h}$. Proteins were wet-transferred onto PVDF membranes (Immobilon-P, Millipore, Billerica, MA, USA) for $1.5 \mathrm{~h}$ at $400 \mathrm{~mA}$. Membranes were blocked by using $5 \%$ non-fat milk. After blocking, the membranes were blotted with $1 / 1000$ diluted primary antibody overnight at $4{ }^{\circ} \mathrm{C}$ and then $1 / 1000$ diluted secondary antibody for $1 \mathrm{~h}$ at RT.

\subsection{Immunofluorescence}

Cells were seeded onto appropriate coverslips assembled in 24-well plates. The next day, cells were fixed with $3.7 \%$ formaldehyde diluted in PBS. Fixed cells were blocked for $1 \mathrm{~h}$ in PBS containing $0.1 \%$ Triton X-100 and 10\% FBS. All primary antibodies, diluted to $1 / 200$ in blocking solution, were added, and the coverslips were incubated at $4{ }^{\circ} \mathrm{C}$ overnight. The next day, the primary antibody was rinsed thoroughly, and the cells were incubated with a species-matching fluorescent secondary antibodies at a ratio of 1/1000 dilution for $1 \mathrm{~h}$ at RT. After rinsing three times with PBS, DAPI staining was performed, and coverslips were mounted onto slides using a mounting medium.

\subsection{Colony Formation}

1500 cells per well were seeded in a 12-well cell culture dish, and colony growth was followed for 3 weeks. Cell culture growth medium was renewed once every 3 days. At the end of 3 weeks, the growth medium was completely removed, and then the cells were washed once with 1X PBS followed by fixation with ice-cold 100\% methanol for $5 \mathrm{~min}$ at $-20{ }^{\circ} \mathrm{C}$. After discarding the fixative, colonies were stained with $0.5 \%(w / v)$ crystal violet dye at room temperature for $20 \mathrm{~min}$.

\subsection{Cell Cycle}

Cells were incubated at $37^{\circ} \mathrm{C}$ with complete RMPI in all cell cycle experiments for $72 \mathrm{~h}$ unless stated otherwise. Parental SNU-475 cells were incubated with RMPI alone or 
with $1.5,3$, and $6 \mu \mathrm{M} \mathrm{R} 428$ at $37^{\circ} \mathrm{C}$ for 24,48 , and $72 \mathrm{~h}$. Cell cycle analysis was performed as described briefly herein. First, cells were trypsinized and collected by centrifugation. Cell pellets were then rinsed and resuspended in PBS and fixed with ice-cold ethanol, added dropwise while vortexing the samples to achieve $70 \%$ final concentration. Cells were initially kept on ice for $15 \mathrm{~min}$ and then at $-20{ }^{\circ} \mathrm{C}$ overnight. The next day, fixed cells were rinsed with PBS and resuspended in PI staining solution containing $50 \mu \mathrm{g} / \mathrm{mL}$ PI, $1 \mathrm{mg} / \mathrm{mL}$ RNAase A, $0.05 \%$ Triton X. Staining was performed at $37^{\circ} \mathrm{C}$ for $45 \mathrm{~min}$. PI staining was evaluated by BD LRS Fortessa (BD Bioscience, San Jose, CA, USA). Analysis was performed by FlowJo v10 (Flowjo, OH, USA) with Watson Pragmatic algorithm.

\subsection{Flow Cytometry}

Cells were collected by trypsinization and washed with PBS. Then, they were incubated with 1/10 PE-conjugated AF154 (FAB154P) antibody in PBS containing 10\% FBS for $30 \mathrm{~min}$ at room temperature. After washing three times with PBS, cells were dissolved in FACS buffer (10\% FBS in PBS), and the PE signal was measured by BD LRS Fortessa.

\subsection{Quantitative Real-Time PCR ( $q P C R$ )}

Total RNA isolation was carried out with the Nucleospin RNA II kit (Macherey-Nagel, Düren, Germany), and $1 \mu \mathrm{g}$ of total RNA was used for cDNA synthesis using RevertAid First Strand cDNA Synthesis Kit (Thermo Scientific, Waltham, MA, USA). Quantitative real-time PCR was performed using 1/10 diluted cDNA, the TaqMan Universal master mix II and Universal Probe Library probes (Roche, Basel, Switzerland) in the ABI PRISM 7500 Fast qPCR System (Thermo Scientific, Waltham, MA, USA) with reaction conditions; $95^{\circ} \mathrm{C}$ for $15 \mathrm{~min}, 50$ cycles of $95^{\circ} \mathrm{C}$ for $15 \mathrm{~s}$ and $60^{\circ} \mathrm{C}$ for $1 \mathrm{~min}$. Primers and probes are shown in Table S1. Fold changes of gene expressions were calculated by $\Delta \Delta \mathrm{Ct}$ method according to GAPDH, which was used as a control for mRNA quantity.

\subsection{Clonality-Proliferation Assay}

Venus positive cells were sorted in a 96-well plate as a single cell/well by BD Cell Sorter ARIAIII. Growth of cell colonies was imaged by Solentim Cell Metric (Solentim, Dorset, UK)

\subsection{Sulforhodamine B Assay}

$3 \times 10^{3}$ cells per well were seeded into 96-well plates. The next day, cells were treated with serially diluted (final concentration: from $10 \mu \mathrm{M}$ to $0.312 \mu \mathrm{M}$ ) AXL inhibitor R428 (HY-15150, MedChemExpress, Princeton, NJ, USA) dissolved in DMSO. After $72 \mathrm{~h}$ of incubation, cells were fixed with 10\% ice-cold trichloroacetic acid (TCA) (T6399, SigmaAldrich, St. Louis, MO, USA) and incubated at $-20^{\circ} \mathrm{C}$ for $20 \mathrm{~min}$. Fixed cells were stained with $0.4 \%$ Sulforhodamine B (SRB) (S1402, Sigma-Aldrich, St. Louis, MO, USA) in 1\% acetic acid (CAS:64-19-7, Sigma-Aldrich, St. Louis, MO, USA ) solution for 20 min. After staining, excess SRB was removed with $1 \%$ acetic acid, and the plates were left to dry. The absorbance in each well was measured after adding $50 \mu \mathrm{L}$ of $10 \mathrm{mM}$ Tris-Base (T1503, Sigma-Aldrich, St. Louis, MO, USA). The OD was measured at 512 nm using Varioskan, FLASH (Thermo Fisher Scientific, Waltham, MA, USA).

\subsection{Animal Studies}

All animal experiments were approved by the IBG Animal Experiments Local Ethics Committee (IBG-AELEC) with protocol number 21/2016. Six to seven months-old NODSCID $\gamma$ male mice bred in the same cage were randomly chosen for injection of REN-4 and AXL-c17 cells, respectively. Initially, respective clones were injected at left and right back $\left(1 \times 10^{6}\right.$ cells for each injection) subcutaneously, using one mouse for each clone. For the following experiments, we performed a single injection of $2 \times 10^{5}$ cells per animal. A total of eight animals (four animals for each clone) were used. Overall, in vivo tumorigenic studies used ten animals. Before injection, cells were harvested in a sub-confluent state 
(70-80\%) and resuspended in $50 \mu \mathrm{L}$ PBS and then mixed with $50 \mu \mathrm{L}$ growth factor-reduced matrigel (356230, Corning, NY, USA). Blinded tumor measurements were carried out twice a week by a technician of IBG vivarium facility.

Supplementary Materials: The following are available online at https:/ / www.mdpi.com/article/10 $.3390 /$ ijms222413247/s1.

Author Contributions: Conceptualization, T.B., S.S., M.O.; data curation, T.B., A.A., U.K. and Z.M.; writing-original draft preparation, T.B. and M.O.; writing-review and editing, M.O., S.S. and H.A.; supervision, M.O., S.S. and H.A. funding acquisition, M.O. All authors have read and agreed to the published version of the manuscript.

Funding: This work was supported by TUBITAK grant No 117S246, funds from the Turkish Academy of Sciences and internal funds of Izmir Biomedicine and Genome Center.

Institutional Review Board Statement: The study was conducted according to the guidelines of the Declaration of Helsinki, and approved by Izmir Biomedicine and Genome Center, Research Program Committee (26 August 2020). All animal experiments were approved by the IBG Animal Experiments Local Ethics Committee (IBG-AELEC) with the protocol number 21/2016.

Informed Consent Statement: Not applicable.

Data Availability Statement: Data supporting the result are available at Izmir Biomedicine and Genome Center archives.

Acknowledgments: We thank Optical Imaging, Flow Cytometry core facilities, IBG-Vivarium Facilities and IBG- Pharma of Izmir Biomedicine and Genome Center.

Conflicts of Interest: The authors declare no conflict of interest.

\section{References}

1. Sung, H.; Ferlay, J.; Siegel, R.L.; Laversanne, M.; Soerjomataram, I.; Jemal, A.; Bray, F. Global Cancer Statistics 2020: GLOBOCAN Estimates of Incidence and Mortality Worldwide for 36 Cancers in 185 Countries. CA Cancer J. Clin. 2021, 71, 209-249. [CrossRef]

2. Kim, D.W.; Talati, C.; Kim, R. Hepatocellular carcinoma (HCC): Beyond sorafenib-Chemotherapy. J. Gastrointest. Oncol. 2017, 8, 256-265. [CrossRef] [PubMed]

3. Zucman-Rossi, J.; Villanueva, A.; Nault, J.-C.; Llovet, J.M. Genetic Landscape and Biomarkers of Hepatocellular Carcinoma. Gastroenterology 2015, 149, 1226-1239.e4. [CrossRef]

4. $\quad$ Llovet, J.M.; Kelley, R.K.; Villanueva, A.; Singal, A.G.; Pikarsky, E.; Roayaie, S.; Lencioni, R.; Koike, K.; Zucman-Rossi, J.; Finn, R.S. Hepatocellular carcinoma. Nat. Rev. Dis. Primers 2021, 7, 6. [CrossRef]

5. El-Khoueiry, A.B.; Hanna, D.L.; Llovet, J.; Kelley, R.K. Cabozantinib: An evolving therapy for hepatocellular carcinoma. Cancer Treat. Rev. 2021, 98, 102221. [CrossRef] [PubMed]

6. Lemke, G. Biology of the TAM receptors. Cold Spring Harb. Perspect. Biol. 2013, 5, a009076. [CrossRef] [PubMed]

7. Lemke, G. How macrophages deal with death. Nat. Rev. Immunol. 2019, 19, 539-549. [CrossRef] [PubMed]

8. Golkowski, M.; Lau, H.-T.; Chan, M.; Kenerson, H.; Vidadala, V.N.; Shoemaker, A.; Maly, D.J.; Yeung, R.S.; Gujral, T.S.; Ong, S.-E. Pharmacoproteomics Identifies Kinase Pathways that Drive the Epithelial-Mesenchymal Transition and Drug Resistance in Hepatocellular Carcinoma. Cell Syst. 2020, 11, 196-207.e7. [CrossRef]

9. Gay, C.M.; Balaji, K.; Byers, L.A. Giving AXL the axe: Targeting AXL in human malignancy. Br. J. Cancer 2017, 116, 415-423. [CrossRef]

10. Liu, J.; Wang, K.; Yan, Z.; Xia, Y.; Li, J.; Shi, L.; Zou, Q.; Wan, X.; Jiao, B.; Wang, H.; et al. Axl expression stratifies patients with poor prognosis after hepatectomy for hepatocellular carcinoma. PLoS ONE 2016, 11, e0154767. [CrossRef]

11. Lee, H.J.; Jeng, Y.M.; Chen, Y.L.; Chung, L.; Yuan, R.H. Gas6/Axl pathway promotes tumor invasion through the transcriptional activation of slug in hepatocellular carcinoma. Carcinogenesis 2014, 35, 769-775. [CrossRef] [PubMed]

12. Xu, J.; Jia, L.; Ma, H.; Li, Y.; Ma, Z.; Zhao, Y. Axl gene knockdown inhibits the metastasis properties of hepatocellular carcinoma via PI3K/Akt-PAK1 signal pathway. Tumor Biol. 2014, 35, 3809-3817. [CrossRef]

13. Goyette, M.-A.; Elkholi, I.E.; Apcher, C.; Kuasne, H.; Rothlin, C.V.; Muller, W.J.; Richard, D.E.; Park, M.; Gratton, J.-P.; Côté, J.-F. Targeting Axl favors an antitumorigenic microenvironment that enhances immunotherapy responses by decreasing Hif- $1 \alpha$ levels. Proc. Natl. Acad. Sci. USA 2021, 118, e2023868118. [CrossRef] [PubMed]

14. Balaji, K.; Vijayaraghavan, S.; Diao, L.; Tong, P.; Fan, Y.; Carey, J.P.W.; Bui, T.N.; Warner, S.; Heymach, J.V.; Hunt, K.K.; et al. AXL inhibition suppresses the DNA damage response and sensitizes cells to PARP inhibition in multiple cancers. Mol. Cancer Res. 2017, 15, 45-58. [CrossRef] [PubMed] 
15. Flem-Karlsen, K.; McFadden, E.; Omar, N.; Haugen, M.H.; Øy, G.F.; Ryder, T.; Gullestad, H.P.; Hermann, R.; Mælandsmo, G.M.; Flørenes, V.A. Targeting AXL and the DNA Damage Response Pathway as a Novel Therapeutic Strategy in Melanoma. Mol. Cancer Ther. 2020, 19, 895-905. [CrossRef]

16. Goyette, M.-A.; Duhamel, S.; Aubert, L.; Pelletier, A.; Savage, P.; Thibault, M.-P.; Johnson, R.M.; Carmeliet, P.; Basik, M.; Gaboury, L.; et al. The Receptor Tyrosine Kinase AXL Is Required at Multiple Steps of the Metastatic Cascade during HER2-Positive Breast Cancer Progression. Cell Rep. 2018, 23, 1476-1490. [CrossRef] [PubMed]

17. Scharf, I.; Bierbaumer, L.; Huber, H.; Wittmann, P.; Haider, C.; Pirker, C.; Berger, W.; Mikulits, W. Dynamics of CRISPR/CAS9mediated genomic editing of the AXL locus in hepatocellular carcinoma cells. Oncol. Lett. 2018, 15, 2441-2450. [CrossRef]

18. Reichl, P.; Dengler, M.; van Zijl, F.; Huber, H.; Führlinger, G.; Reichel, C.; Sieghart, W.; Peck-Radosavljevic, M.; Grubinger, M.; Mikulits, W. Axl activates autocrine transforming growth factor- $\beta$ signaling in hepatocellular carcinoma. Hepatology 2015, 61, 930-941. [CrossRef]

19. He, L.; Zhang, J.; Jiang, L.; Jin, C.; Zhao, Y.; Yang, G.; Jia, L. Differential expression of Axl in hepatocellular carcinoma and correlation with tumor lymphatic metastasis. Mol. Carcinog. 2010, 49, 882-891. [CrossRef]

20. Caruso, S.; Calatayud, A.-L.; Pilet, J.; La Bella, T.; Rekik, S.; Imbeaud, S.; Letouzé, E.; Meunier, L.; Bayard, Q.; Rohr-Udilova, N.; et al. Analysis of Liver Cancer Cell Lines Identifies Agents with Likely Efficacy Against Hepatocellular Carcinoma and Markers of Response. Gastroenterology 2019, 157, 760-776. [CrossRef]

21. O’Bryan, J.P.; Frye, R.A.; Cogswell, P.C.; Neubauer, A.; Kitch, B.; Prokop, C.; Espinosa, R.; Le Beau, M.M.; Earp, H.S.; Liu, E.T. Axl, a Transforming Gene Isolated From Primary Human Myeloid Leukemia Cells, Encodes a Novel Receptor Tyrosine Kinase. Mol. Cell. Biol. 1991, 11, 5016-5031. [CrossRef] [PubMed]

22. Müller, S.; Almouzni, G. Chromatin dynamics during the cell cycle at centromeres. Nat. Rev. Genet. 2017, 18, 192-208. [CrossRef]

23. Kuerbitz, S.J.; Plunkett, B.S.; Walsh, W.V.; Kastan, M.B. Wild-type p53 is a cell cycle checkpoint determinant following irradiation. Proc. Natl. Acad. Sci. USA 1992, 89, 7491-7495. [CrossRef] [PubMed]

24. Lowe, S.W.; Bodis, S.; McClatchey, A.; Remington, L.; Ruley, H.E.; Fisher, D.E.; Housman, D.E.; Jacks, T. p53 Status and the Efficacy of Cancer Therapy in Vivo. Science 1994, 266, 807-810. [CrossRef]

25. Illidge, T.M.; Cragg, M.S.; Fringes, B.; Olive, P.; Erenpreisa, J.A. Polyploid giant cells provide a survival mechanism for p53 mutant cells after DNA damage. Cell Biol. Int. 2000, 24, 621-633. [CrossRef]

26. Hwang, S.-J.; Lozano, G.; Amos, C.I.; Strong, L.C. Germline p53 Mutations in a Cohort with Childhood Sarcoma: Sex Differences in Cancer Risk. Am. J. Hum. Genet. 2003, 72, 975-983. [CrossRef] [PubMed]

27. Sancar, A.; Lindsey-Boltz, L.A.; Ünsal-Kaçmaz, K.; Linn, S. Molecular Mechanisms of Mammalian DNA Repair and the DNA Damage Checkpoints. Annu. Rev. Biochem. 2004, 73, 39-85. [CrossRef]

28. Gire, V.; Dulic, V. Senescence from G2 arrest, revisited. Cell Cycle 2015, 14, 297-304. [CrossRef]

29. Holland, S.J.; Pan, A.; Franci, C.; Hu, Y.; Chang, B.; Li, W.; Duan, M.; Torneros, A.; Yu, J.; Heckrodt, T.J.; et al. R428, a Selective Small Molecule Inhibitor of Axl Kinase, Blocks Tumor Spread and Prolongs Survival in Models of Metastatic Breast Cancer. Cancer Res. 2010, 70, 1544-1554. [CrossRef] [PubMed]

30. Lin, Z.Y.; Chuang, W.L. Genes responsible for the characteristics of primary cultured invasive phenotype hepatocellular carcinoma cells. Biomed. Pharmacother. 2012, 66, 454-458. [CrossRef]

31. Pinato, D.J.; Brown, M.W.; Trousil, S.; Aboagye, E.O.; Beaumont, J.; Zhang, H.; Coley, H.M.; Mauri, F.A.; Sharma, R. Integrated analysis of multiple receptor tyrosine kinases identifies Axl as a therapeutic target and mediator of resistance to sorafenib in hepatocellular carcinoma. Br. J. Cancer 2019, 120, 512-521. [CrossRef]

32. Hsu, C.; Hsieh, P.; Chen, Y.; Lo, G.; Lin, H.; Dai, C.; Huang, J.; Chuang, W.; Chen, Y.; Yu, M.; et al. Axl and autophagy LC3 expression in tumors is strongly associated with clinical prognosis of hepatocellular carcinoma patients after curative resection. Cancer Med. 2019, 8, 3453-3463. [CrossRef]

33. Staufer, K.; Dengler, M.; Huber, H.; Marculescu, R.; Stauber, R.; Lackner, C.; Dienes, H.-P.; Kivaranovic, D.; Schachner, C.; Zeitlinger, M.; et al. The non-invasive serum biomarker soluble Axl accurately detects advanced liver fibrosis and cirrhosis. Cell Death Dis. 2017, 8, e3135. [CrossRef]

34. Dengler, M.; Staufer, K.; Huber, H.; Stauber, R.; Bantel, H.; Weiss, K.H.; Starlinger, P.; Pock, H.; Plachky, P.K.; Gotthardt, D.N.; et al. Soluble Axl is an accurate biomarker of cirrhosis and hepatocellular carcinoma development: Results from a large scale multicenter analysis. Oncotarget 2017, 8, 46234-46248. [CrossRef]

35. Song, X.; Wu, A.; Ding, Z.; Liang, S.; Zhang, C. Soluble Axl Is a Novel Diagnostic Biomarker of Hepatocellular Carcinoma in Chinese Patients with Chronic Hepatitis B Virus Infection. Cancer Res. Treat. 2020, 52, 789-797. [CrossRef]

36. Xu, M.Z.; Chan, S.W.; Liu, A.M.; Wong, K.F.; Fan, S.T.; Chen, J.; Poon, R.T.; Zender, L.; Lowe, S.W.; Hong, W.; et al. AXL receptor kinase is a mediator of YAP-dependent oncogenic functions in hepatocellular carcinoma. Oncogene 2011, 30, 1229-1240. [CrossRef] [PubMed]

37. Xu, W.; Jiang, X.; Huang, L. RNA interference technology. In Comprehensive Biotechnology; Elsevier: Amsterdam, The Netherlands, 2019; ISBN 9780444640475.

38. Ramkumar, K.; Stewart, C.A.; Cargill, K.R.; Della Corte, C.M.; Wang, Q.; Shen, L.; Diao, L.; Cardnell, R.J.; Peng, D.H.; Rodriguez, B.L.; et al. AXL Inhibition Induces DNA Damage and Replication Stress in Non-Small Cell Lung Cancer Cells and Promotes Sensitivity to ATR Inhibitors. Mol. Cancer Res. 2021, 19, 485-497. [CrossRef] [PubMed] 
39. Kariolis, M.S.; Miao, Y.R.; Diep, A.; Nash, S.E.; Olcina, M.M.; Jiang, D.; Ii, D.S.J.; Kapur, S.; Mathews, I.I.; Koong, A.C.; et al. Inhibition of the GAS6/AXL pathway augments the efficacy of chemotherapies. J. Clin. Investig. 2017, 127, 183-198. [CrossRef] [PubMed]

40. Middleton, A.; Suman, R.; O’Toole, P.; Akopyan, K.; Lindqvist, A. p53-dependent polyploidisation after DNA damage in G2 phase. bioRxiv 2020. [CrossRef]

41. Oz, O.; Iscan, E.; Batur, T.; Ozturk, M. 3d organoid modelling of hepatoblast-like and mesenchymal-like hepatocellular carcinoma cell lines. Hepatoma Res. 2021, 7, 60. [CrossRef]

42. Iscan, E.; Ekin, U.; Yildiz, G.; Oz, O.; Keles, U.; Suner, A.; Cakan-Akdogan, G.; Ozhan, G.; Nekulova, M.; Vojtesek, B.; et al. TAp73 $\beta$ Can Promote Hepatocellular Carcinoma Dedifferentiation. Cancers 2021, 13, 783. [CrossRef] [PubMed]

43. Senturk, S.; Shirole, N.H.; Nowak, D.G.; Corbo, V.; Pal, D.; Vaughan, A.; Tuveson, D.A.; Trotman, L.C.; Kinney, J.B.; Sordella, R. Rapid and tunable method to temporally control gene editing based on conditional Cas9 stabilization. Nat. Commun. 2017, 8 , 14370. [CrossRef] [PubMed]

44. Shalem, O.; Sanjana, N.E.; Hartenian, E.; Shi, X.; Scott, D.A.; Mikkelsen, T.S.; Heckl, D.; Ebert, B.L.; Root, D.E.; Doench, J.G.; et al. Genome-scale CRISPR-Cas9 knockout screening in human cells. Science 2014, 343, 84-87. [CrossRef] [PubMed] 